\title{
Socialização de conceitos de microbiologia no ensino fundamental através de atividades práticas
}

\author{
Isa Carolina Gomes Felix ${ }^{1}$ (D) Alyne Barbosa Brito ${ }^{1}$ (D) , Tatiana Farias de Oliveira ${ }^{1}$ (D) , Brenda Emily Dias Tavares ${ }^{1}$ (D), \\ Kelly Fernanda Seára da Silva ${ }^{\text {(D) , Mayanne Karla da Silva }}{ }^{\text {(D) , Aline Cavalcanti de Queiroz }}{ }^{\text {(iD) }}$, Alysson Wagner \\ Fernandes Duarte ${ }^{2}$ (D)
}

\begin{abstract}
Resumo: As abordagens tradicionais de ensino tendem a ser menos estimulantes e de maior dificuldade de compreensão, principalmente ao tratar-se de assuntos mais distantes da realidade dos alunos e, de certa forma, abstratos, como alguns conceitos de Microbiologia. Tal realidade reforça a importância do estudo e aplicação de novas formas de ensino no ambiente escolar. Nesse sentido, o objetivo deste artigo é relatar a experiência de ações de extensão realizadas com o tema "Dia do Cientista", nas quais os métodos utilizados foram baseados no protagonismo dos alunos, através da participação ativa em experimentos, discussões e visitações. Ao longo da execução das ações, observou-se o despertar do interesse em assuntos até então desconhecidos e distantes da realidade dos estudantes do Ensino Fundamental I (4. e 5. ano), que puderam reconhecer o que a Microbiologia representa no seu cotidiano, a partir da execução de atividades práticas, como: I) Detecção de microrganismos em diferentes espaços da escola, como salas de aula e dos professores, banheiros e pátio; II) "Carimbo de mãos"; III) Utilização de fermento biológico para o crescimento microbiano e IV) Visita à Universidade Federal de Alagoas - Campus Arapiraca, onde puderam conhecer laboratórios de ensino prático do tema. Dessa forma, percebeu-se que estratégias com abordagens ativas e práticas auxiliaram numa maior interação dos alunos com os temas propostos, além de aguçar a curiosidade, estimular o aprendizado e permitir maior crescimento pessoal por parte dos escolares, bem como de todos os participantes do projeto.
\end{abstract}

Palavras-chave: Extensão comunitária; Ensino; Aprendizagem

\section{Socialization of microbiology concepts in elementary school through practical activities}

Abstract: Traditional teaching approaches tend to be less stimulating and more difficult to understand, especially when dealing with subjects that are more distant from the reality of students and, in a way, abstract, such as some topics of microbiology. This reality reinforces the importance of studying and applying new forms of teaching in the school environment. In this sense, the objective of this article is to report the experience of extension actions carried out with the theme "Scientist's Day", in which the methods used were based on the protagonism of the students, through active participation in experiments, discussions, and visits. Throughout the actions, it was possible to notice an awakening of interest in subjects previously unknown and distant from the reality of the students at elementary school (4th and 5th), who were able to recognize what microbiology represents in their daily lives, from the execution of practical activities such as I) Detection of microorganisms in different locations of the school, such as classrooms and teachers' room, bathrooms and courtyard; II) "Hand Stamp"; III) Use of biological yeast for microbial growth and IV) Visit to the Federal University of Alagoas - Campus Arapiraca (Arapiraca, Brazil), where they got to know the laboratories. Therefore, it was noticed that strategies with active and practical approaches made the interaction of students with the proposed themes easier, besides to whet curiosity, stimulate learning and allow greater personal growth by the schoolers, as well as all the participants of the project.

Keywords: Community extension; Teaching; Learning
Originais recebidos em

21 de março de 2020

Aceito para publicação em

17 de junho de 2020

1

Universidade Federal de Alagoas - UFAL, Campus Arapiraca.

2

Universidade Federal de Alagoas - UFAL, Campus Arapiraca. Avenida Manoel Severino Barbosa s/n, Bom Sucesso, CEP 57309-005, Arapiraca, Alagoas, Brasil.

alysson.duarte@arapiraca.ufal.br (autor para correspondência) 


\section{Introdução}

A educação em saúde deve ser compreendida como uma importante vertente para a prevenção de doenças e agravos, cuja prática está atrelada a melhores condições de vida e de saúde da população (Oliveira \& Gonçalves, 2004). Da mesma forma, como processo político e pedagógico, requer a construção de um pensar crítico e reflexivo que permita ao sujeito identificar os elementos determinantes para a saúde e transformar sua realidade, passando assim a ser um sujeito autônomo, emancipado, capaz de cuidar de si e de sua comunidade (Candeias, 1997).

Um espaço importante para o desenvolvimento de ações de educação em saúde é a escola, onde é possível levar estudantes e comunidade a desenvolverem conhecimentos e habilidades em relação a hábitos saudáveis, de modo a refletirem sobre os comportamentos ligados à saúde e a adotarem mudanças positivas para sua vida, uma vez que o período da infância e adolescência é de extrema relevância no crescimento e desenvolvimento do indivíduo (Gubert et al., 2009).

Nesse contexto, Cassanti et al. (2008) afirmam que, apesar de sua grande importância, a Microbiologia tem sido negligenciada pelos professores e isso pode ser um reflexo da dificuldade do desenvolvimento de estratégias de ensino-aprendizagem que facilitem a compreensão dos alunos. Ademais, a falta de conexão entre a Microbiologia e o dia a dia do aluno torna essa disciplina muito abstrata, o que, certamente, dificulta ainda mais o aprendizado do educando, pois não existe uma conexão entre essa temática e o cotidiano, por parte do aluno, transformando o conteúdo em algo abstrato e teórico.

Nesse sentido, o conhecimento sobre o "mundo microbiano", apesar da sua relevância e variedade de assuntos, inclusive relacionados diretamente à saúde humana, é conduzido de forma pouco compreensível (Fahnert, 2016) e com uma abordagem predominantemente teórica e descontextualizada da realidade diária do aluno, tornando-o pouco atrativo (Moresco et al., 2017; Firmanshah et al., 2020; Leite \& Valente, 2020). Algumas justificativas acentuam essa problemática: como estudar organismos microscópicos sem microscópios? Como comprovar que esses organismos existem sem laboratórios de ciências apropriados? Como comprovar que eles estão por todo lugar, inclusive em nossas mãos, se não conseguimos visualizá-los a olho nu e faltam recursos para a realização de experimentos?

Esses foram alguns dos questionamentos que impulsionaram a proposição do projeto de extensão "O mundo microbiano no ambiente escolar". Dessa forma, a realização do projeto foi justificada a partir do entendimento da necessidade existente de oxigenar saberes e práticas acerca de temas relacionados à Microbiologia, munindo-se de metodologias didáticas diferenciadas para tal, em virtude das dificuldades existentes no ensino dos conteúdos dessa área na Educação Básica. Frente a esses pressupostos, o objetivo deste trabalho é descrever as atividades de extensão intituladas "Dia do Cientista", desenvolvidas com crianças de uma escola do Ensino Fundamental em Arapiraca-AL.

\section{Procedimentos Metodológicos}

O projeto "O mundo microbiano no ambiente escolar", desenvolvido na escola Jayme de Altavilla (Ensino Fundamental I), localizada no município de Arapiraca, Alagoas, Brasil, faz parte do Programa Círculos Comunitários de Atividades Extensionistas, da Universidade Federal de Alagoas (UFAL), Campus Arapiraca e contou, no momento do desenvolvimento das atividades relatadas, com alunos dos cursos de Medicina, Enfermagem e Biologia.

Este trabalho trata-se de um relato de experiência acerca das ações direcionadas a um público que incluiu quatro turmas de, aproximadamente, 40 alunos cada, com idades de 9 a 12 anos, e que foram acompanhados 
do $4^{\circ}$ ao $5^{\circ}$ ano do Ensino Fundamental I. Os temas trabalhados reportaram-se à Microbiologia e seus diferentes aspectos, relacionados ao cotidiano humano.

Inicialmente, aplicou-se um questionário com ilustrações para análise dos conhecimentos prévios dos alunos em relação à Microbiologia (Material Suplementar S1) e, após isto, as abordagens dos temas ocorreram mediante estratégias didáticas de ensino, como aulas práticas, jogos educativos, palestras, oficinas e utilização de plataformas on-line de jogos, como o kahoot, além da visita dos escolares aos laboratórios da Universidade.

Dentre as atividades executadas, três momentos foram relatados como "Dia do Cientista": o primeiro, referiuse à realização do questionamento aos estudantes de "onde os microrganismos estão?". Foi proposto, então, para auxiliar na resposta, a detecção de microrganismos em diferentes locais da escola. Perguntou-se aos alunos quais lugares eles achavam que teriam microrganismos e os principais foram os banheiros, o pátio da escola, a sala de aula e sala dos professores. Para demonstrar a presença dos microrganismos nestes ambientes foram utilizadas placas de Petri com meio de cultura ágar nutriente, que permaneceram abertas durante tempos diferentes (10, 30, 60 e 120 minutos) nos locais escolhidos. Ainda no mesmo dia, os alunos 'carimbaram' as mãos, sem higienização prévia, nas placas e, ao final da ação, o material foi levado à UFAL para incubação e, após 1 semana, foram apresentadas aos alunos, para visualização e discussão dos resultados do crescimento de microrganismos, provenientes do ambiente e das mãos dos alunos.

No segundo momento, realizou-se um experimento para avaliar o crescimento de microrganismos em diferentes meios. Para tanto, utilizou-se água morna, fermento biológico, açúcar, adoçante, balões e tubos para colocar as misturas: Tubo 1. água morna e fermento; Tubo 2. água morna, fermento e açúcar; Tubo 3. água morna, fermento e adoçante aspartame, e questionou-se aos alunos em qual deles haveria crescimento dos microrganismos presentes no fermento biológico. Os alunos foram responsáveis, mediante supervisão, por realizarem as misturas nos tubos e encaixarem, na parte superior de cada tubo, um balão para comprovarem em qual deles haveria crescimento, através do enchimento do balão.

Por fim, o terceiro momento ocorreu durante uma visita guiada à Universidade Federal de Alagoas, Campus Arapiraca, onde os alunos puderam conhecer o laboratório de microscopia e visualizar alguns dos microrganismos estudados através de um microscópio, pela primeira vez.

Além disso, foram realizadas ações contínuas na mesma escola, com a aplicação de um jogo da memória para trabalhar conceitos de higiene, no qual cada carta do jogo possuía um desenho e uma frase relacionada. Ao final do primeiro ciclo do projeto, os alunos desenharam em cartolina as ações que mais chamaram sua atenção.

\section{Resultados}

Como resultados das ações de extensão, notou-se que houve, no primeiro momento, uma limitação na interação entre os alunos e os membros do projeto de extensão, supondo-se a projeção, por parte dos escolares, que a abordagem seria basicamente teórica, através do método tradicional de ensino, em que o educador é o detentor do conhecimento e posteriormente transmite aos estudantes. Todavia, com a frequência das ações nas escolas e a proposta diferenciada das atividades, os alunos eram sempre estimulados a serem sujeitos ativos no processo de ensino-aprendizagem e, com isso, observou-se um desenvolvimento mais crítico e autônomo por parte deles.

Ao serem questionados, inicialmente, pelo grupo, sobre o que eles acreditavam que eram microrganismos, não raras eram as associações com insetos, lagartixas e minhocas e a maioria acreditava que eram "bichos" e que habitavam locais, como a natureza e lugares sujos. A primeira ação realizada, relacionada à detecção de microrganismos nos diferentes ambientes da escola (Figura 1) e das mãos dos alunos, nos ajudaram a 
comprovar aos alunos que os microrganismos estão mais presentes em nossas vidas do que eles suspeitavam, e que, por serem seres microscópicos, não conseguimos visualizá-los a olho nu.

Com a exposição das placas com várias colônias presentes, os membros do projeto discutiram os questionamentos que surgiram e explicaram que cada microrganismo tinha uma coloração e característica específica no meio de cultura e ali havia diferentes organismos, principalmente bactérias e que, mesmo sendo seres tão pequenos, com sua multiplicação na placa contendo meio de cultura era possível visualizar as colônias formadas por eles. Com o intuito de reforçar o exposto, foi exibido, posteriormente, um vídeo preparado pela equipe do projeto que respondia a três questionamentos: 1 . O que são os microrganismos? 2. Onde estão? 3. O que fazem? O vídeo ${ }^{1}$ foi incluído no canal do projeto de extensão no youtube ${ }^{2}$, e atualmente (07/06/2020) possui mais de 50.000 visualizações.

Ainda nesta ação, foi realizado o "carimbo das mãos", onde alguns alunos colocaram suas mãos sem higienização prévia em placas de Petri com meio de cultura (Figura 2).

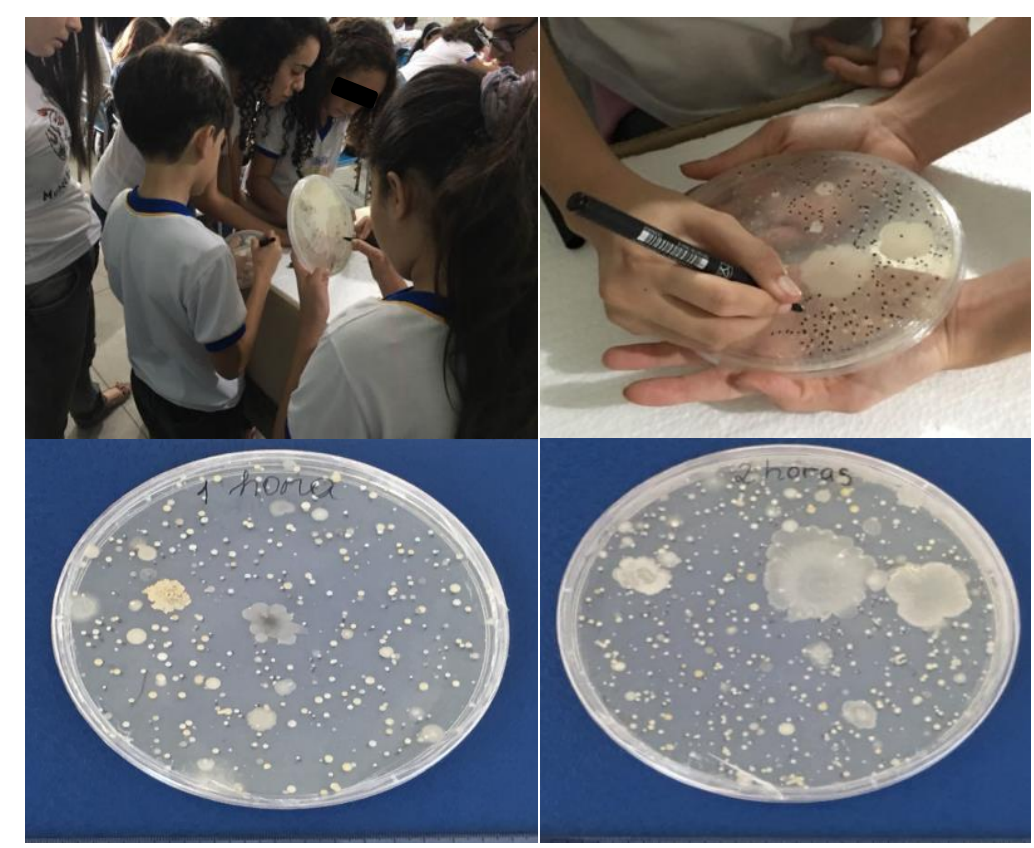

Figura 1. Ação "Detecção de microrganismos em diferentes espaços da escola". Participação dos alunos durante as ações do projeto "O Mundo microbiano no ambiente Escolar".com contagem de colônias nas diferentes placas com meio de cultura e expostas nos diferentes ambientes das escolas. Fonte: Autores (2019).
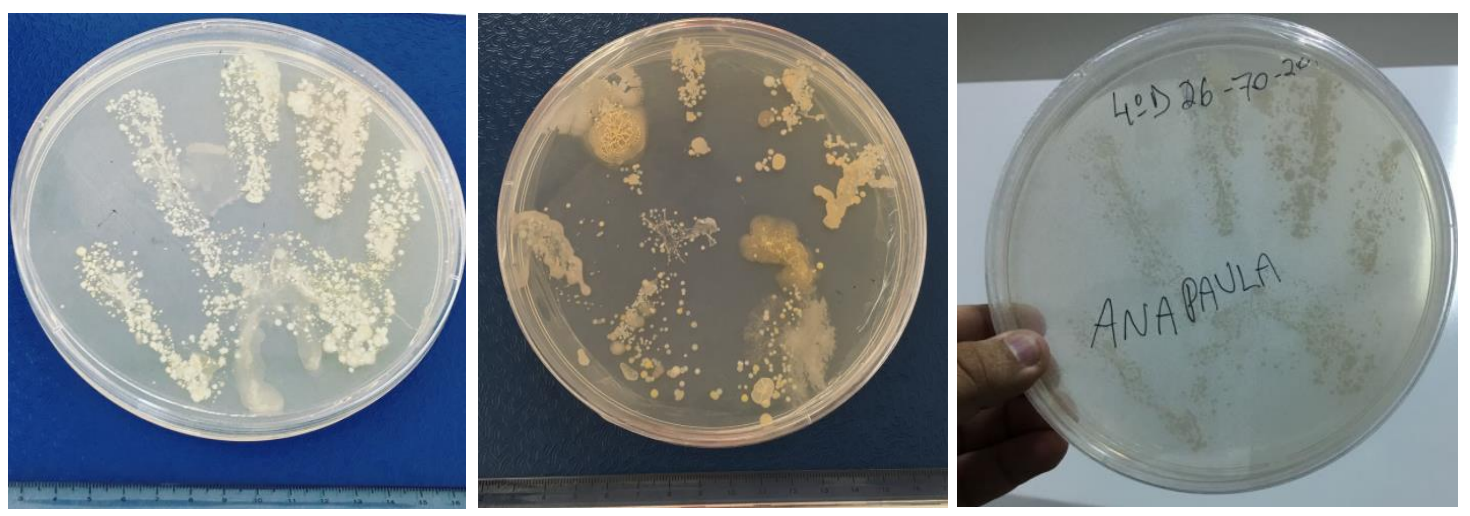

Figura 2. Ação 'Carimbos de mãos'. Mãos de alunos de ensino fundamental, antes da higienização, em placas de Petri contendo meio de cultura, e incubadas durante 7 dias a $25^{\circ} \mathrm{C}$. Fonte: Autores (2019). 
Após verem os microrganismos que haviam crescido de suas "mãos limpas" nas placas, a discussão ficou mais rica e alguns começaram a questionar como havia crescido microrganismos se suas mãos não estavam visivelmente sujas. Diante disso, foi discutido e explicado que os microrganismos estão por todo o nosso corpo e que as mãos são as principais formas de transmissão de microrganismos, pois estamos o tempo todo manuseando algum objeto e, por isso, é essencial que façamos a higiene correta das mãos, especialmente após usar o banheiro ou antes de qualquer refeição.

Em relação ao segundo momento, os alunos foram convidados a lerem o protocolo do experimento "Como os microrganismos crescem?" para entenderem o que iriam desenvolver (Figura 3). Os alunos foram provocados com alguns questionamentos: Em qual tubo haverá crescimento microbiano (fermentação)? Por que há formação de gás na bexiga? Será que haverá gás na bexiga de todos os tubos, ou somente naqueles que têm açúcar ou adoçante? Por que utilizar água morna para o experimento? Se fosse água gelada, teríamos o mesmo resultado? Qual microrganismo está presente no fermento usado?
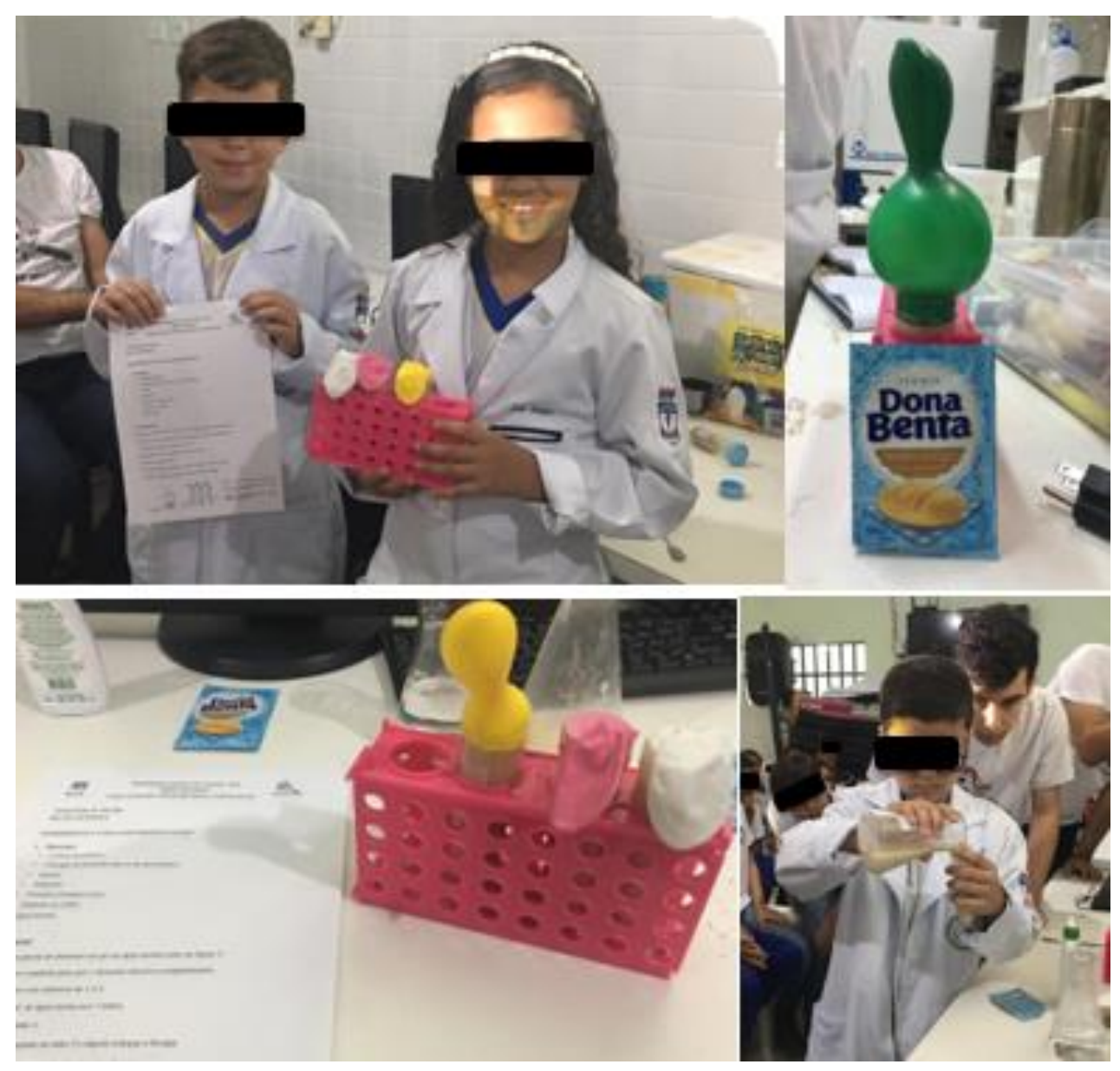

Figura 3. Execução do experimento de crescimento microbiano utilizando fermento biológico. Fonte: Autores (2019).

Cerca de uma hora após o início do experimento, os alunos começaram a observar que apenas a bexiga contendo a solução de fermento biológico com açúcar apresentava formação de gás. Foi, então, discutido com eles o processo de crescimento e fermentação, através do exemplo de uma levedura usada para fazer pão, e que a formação de gás ocorria devido ao consumo do açúcar pela levedura, produzindo o gás carbônico. Foi explicada, também, a razão de usar água morna e que, se fosse água gelada, certamente a levedura não iria 
produzir gás em um tempo relativamente curto, já que todo microrganismo tem uma temperatura ótima para crescer. Foi muito significativo para a equipe do projeto perceber os semblantes dos alunos, maravilhados ao presenciarem o enchimento da bexiga.

O último encontro do "Dia do Cientista" foi marcado pela visita da turma às instalações da Universidade Federal de Alagoas, Campus Arapiraca. Os alunos fizeram um roteiro guiado pelos laboratórios da instituição, particularmente o Laboratório de Microscopia, para visualização de alguns microrganismos em microscópios de campo claro. Quando perguntados se já tinham vindo até a Universidade, a maioria relatou não conhecer e que este era, inclusive, o primeiro momento que tiveram acesso a um microscópio.

A visita contou com uma aula reforçando o que eram e quão importantes os microrganismos são para o ambiente e para a saúde. Após isso, fizeram o manuseio do microscópio e observaram lâminas pré-preparadas e coradas de grupos microbianos, como as bactérias e os fungos, o que gerou muito entusiasmo e curiosidade com as novidades e levou a muitos questionamentos sobre aquilo que estavam visualizando.

Anteriormente a essa visita à Universidade, foi solicitado aos alunos que, em grupo, desenhassem em cartazes aquilo que mais tinha chamado a atenção durante as diferentes ações realizadas na escola. Esses cartazes foram expostos nos corredores da Universidade durante a visita deles, e indicavam que as ações mais marcantes foram aquelas trabalhadas como "Dia do Cientista", com destaque às ações práticas, como a "dos balões" e o "carimbo das mãos" (Figura 4).

Outras ações realizadas incluíram jogo de memória sobre temas relacionados à higiene (Figura 5), utilização de plataformas on-line de jogos, como o kahoot, que facilitaram o encontro da Microbiologia e o cotidiano dos alunos.

\section{Discussão}

A partir dessas atividades, temas como crescimento microbiano e a importância da adequada higienização das mãos foram trabalhados junto aos alunos participantes, comprovando a eles que, embora não sejam visualizados a olho nu, os microrganismos estão em todos os locais dos espaços físicos que nos cercam, até em contato com a nossa pele, mesmo após o processo de limpeza, ou mesmo nos locais considerados mais limpos pelos estudantes. Kaufmann et al. (2016) fizeram uma abordagem semelhante com uma turma de sétimo ano, em que os alunos coletaram amostras de diferentes fontes que achassem interessante (celular, saliva, sala de aula e outros) na escola e observaram a existência de bactérias nesses meios, após o cultivo em placas. Concluíram afirmando que experimentos desse tipo acrescentam aos "(...) alunos informações de realidade e de experiência pessoal', reforçando o papel dessas estratégias no processo de ensinoaprendizagem sobre o mundo microbiano de uma forma mais simples e significativa.

Similarmente, Barbosa e Oliveira (2015) utilizaram a exposição de um vídeo didático para ilustrar os seres microscópicos para duas turmas de sexto ano em uma escola fundamental, em Goiás, acompanhada da observação do crescimento dos microrganismos em placas de Petri de amostras coletadas das mãos, saliva e da escola dos alunos. Segundo as autoras, isso possibilitou que os alunos percebessem que, ao seu redor, há microrganismos, o que contribuiu na construção de uma imagem mais concreta das informações teóricas recebidas no vídeo e abordadas pelo professor.

O intuito da realização de atividades práticas, como o experimento "Como os microrganismos crescem?" (Figura 5) é de facilitar aos alunos a compreensão de temas mais complexos, e contribuir para a aproximação da Microbiologia com seu cotidiano. Como exemplo, a observação da fermentação biológica, através do enchimento das bexigas por gás, auxilia na compreensão das atividades realizadas por um microrganismo chave presente no fermento, que são as leveduras, um dos principais microrganismos benéficos envolvidos na 
produção de alimentos fermentados, como os pães e laticínios. Este modelo de prática corrobora com a aquisição de uma visão diferenciada do papel biológico dos microrganismos, do modo como atuam e desempenham processos benéficos para nós, e não apenas como causadores de doenças. Abordagens dessa natureza estimulam nas crianças mudanças de suas perspectivas, possibilitam que se tornem aptas a questionarem fenômenos, busquem respostas e fortaleçam a aprendizagem dos conteúdos estudados (Freitas et al., 2018).

A)

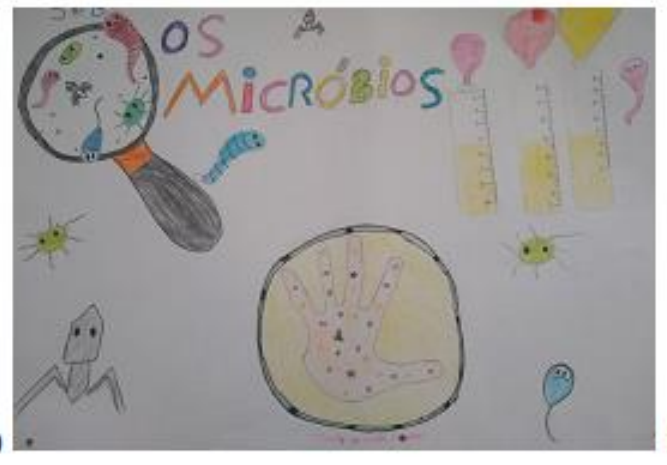

B)

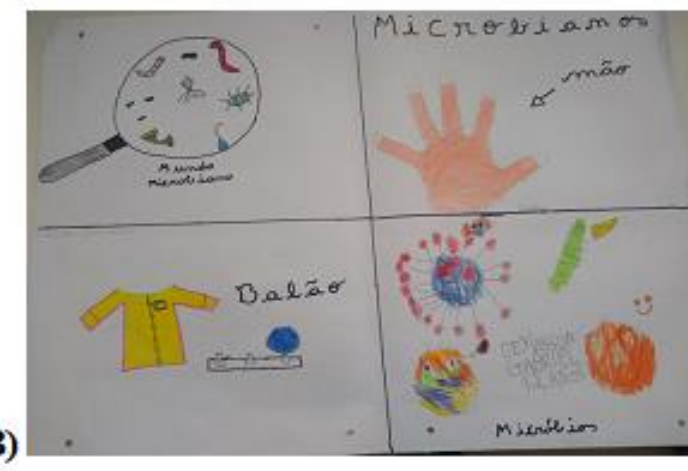

D)

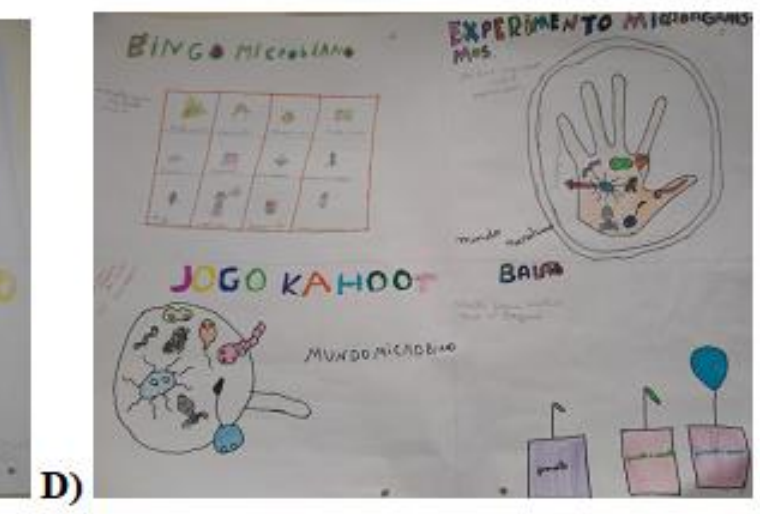

C)

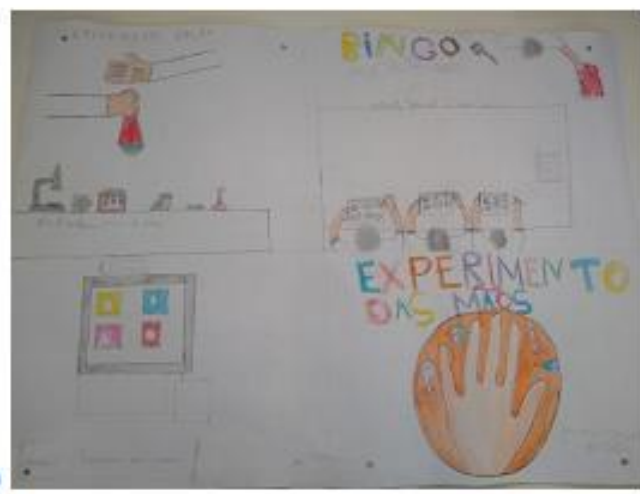

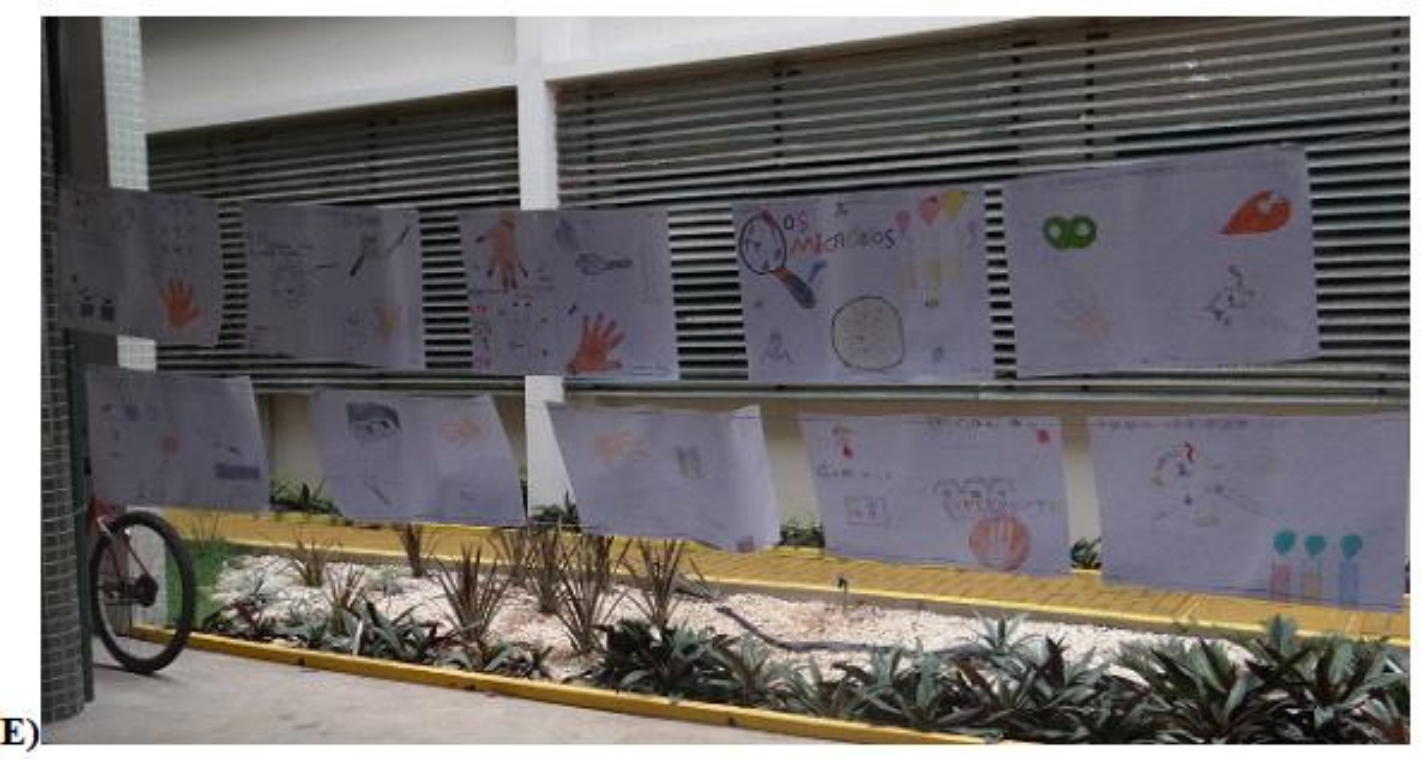

Figura 4. Cartazes desenhados pelos alunos do 5 ano do ensino fundamental I destacando as ações do projeto "O mundo microbiano no ambiente escolar" que foram mais marcantes. A-D) Cartazes desenhados pelos alunos; E) Exposição dos cartazes durante a visita dos alunos à Universidade Federal de Alagoas, Campus Arapiraca. Fonte: Autores (2019). 

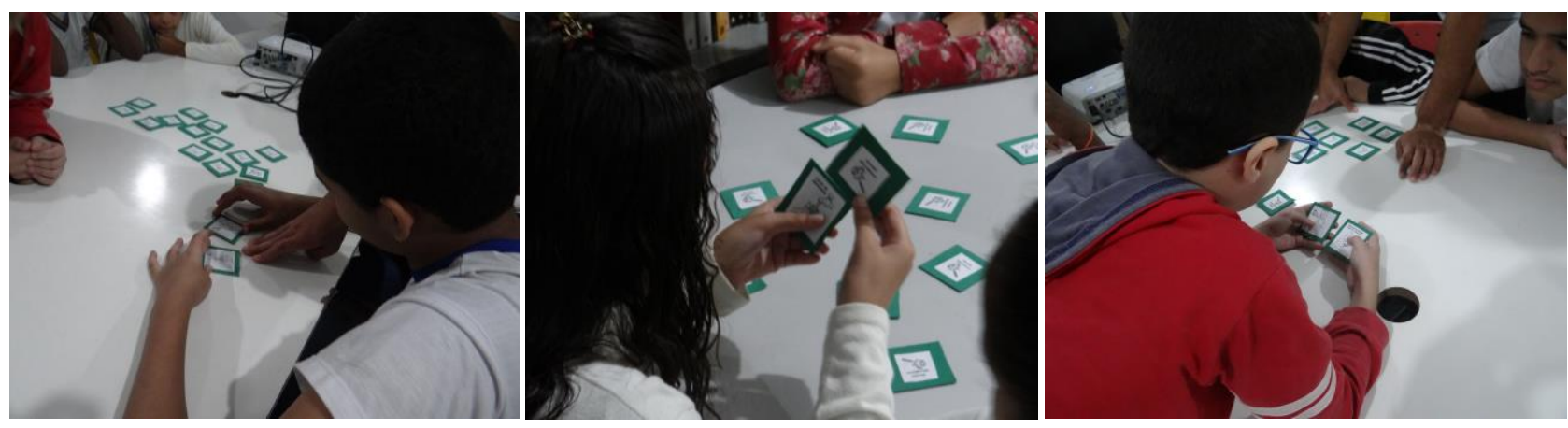

Figura 5. Aplicação de jogo da memória. Fonte: Autores (2019).

Outrossim, Prates-Júnior et al. (2018), através da abordagem extensionista com temas relacionados à Microbiologia e Agroecologia, relataram que o conhecimento a partir de situações problema, combinadas com atividades práticas, podem proporcionar aos alunos um momento de ressignificação de conceitos prévios, possibilitando uma maior aproximação do saber científico, prioritariamente acadêmico, com o espaço escolar e, em um segundo momento, desse conhecimento com a comunidade, favorecendo a democratização do conhecimento.

Percebeu-se, também, que a atuação da universidade de maneira mais próxima da comunidade possibilitou um entendimento maior sobre sua importância e benefícios que, até então, eram desconhecidos por alguns. Isso ampliou a curiosidade e as perspectivas das crianças em relação às temáticas trabalhadas e aos seus futuros, de um modo geral. Assim, a proposta da extensão é, então, efetivada, por criar essa comunicação direta e construtiva entre a universidade e a comunidade, disseminando o saber científico produzido dentro dela através dos futuros propagadores desse saber, que serão essas crianças (Arruda-Barbosa et al., 2019).

\section{Considerações Finais}

Perante as ações desenvolvidas durante o projeto de extensão, verificamos que conceitos básicos sobre os microrganismos puderam ser trabalhados através de abordagens mais estimulantes e atrativas aos alunos, utilizando metodologias didáticas diferenciadas que transformam o conhecimento microbiológico em algo mais tangível, ao passo que aproxima o conteúdo das experiências diárias, tornando-o mais significativo para as crianças. Notou-se que essas experiências aguçam a curiosidade, o aprendizado e criam possibilidades que levam a um efeito positivo nos aspectos pessoais, escolares e sociais das crianças envolvidas, bem como nos acadêmicos participantes do projeto que passaram a conhecer a realidade de parte da comunidade a qual fazem parte e que serão atuantes em suas formações profissionais. Nesse sentido, reforçamos o papel de iniciativas dessa natureza como força transformadora no ensino convencional de conteúdos voltados à Microbiologia e da interação entre escolas de ensino fundamental e as universidades.

\section{Agradecimentos}

Agradecemos à citada escola, pela permissão e contribuição com nosso projeto; aos alunos, peças centrais e razão pela qual tudo isso foi construído; aos colaboradores e coordenadores do projeto, por toda dedicação em cada ação realizada e à Universidade Federal de Alagoas, pelo incentivo à realização de projetos de extensão através do Edital ProCCAExt 2018, e por nos proporcionar esta valiosa oportunidade. 


\section{Contribuições de cada autor}

Os autores 1, 2, 3, 4, 5 e 6 contribuíram com a escrita do texto e a descrição das ações realizadas. 0 autor 1 contribuiu com a revisão final do texto e padronização de acordo com as normas exigidas. Os autores 7 e 8 contribuíram com a idealização, planejamento e execução do projeto, assim como, com a revisão textual.

\section{Notas \\ ${ }^{1}$ https://www.youtube.com/watch?v=CvRiuKrU6jM\&t=30s \\ ${ }^{2}$ https://www.youtube.com/channel/UC1yEVyQ50W YR9y1sEA07UA}

\section{Referências}

Arruda-Barbosa, L., Salles, M. C., de Souza, I. L. L., Dondim-Sales, A. F., da Silva, G. C. N., \& de Lima-Júnior, M. M. (2019). Extensão como ferramenta de aproximação da universidade com o ensino médio. Caderno de Pesquisa, 49(174), 316327.

Barbosa, F. G., \& Oliveira, N. C. (2015). Estratégias para o Ensino de Microbiologia: Uma Experiência com Alunos do Ensino Fundamental em uma Escola de Anápolis-GO. UNOPAR Científica Ciências Humanas e Educação, 16(1), 5-13.

Candeias, N. M. F. (1997). Conceitos de educação e de promoção em saúde: Mudanças individuais e mudanças organizacionais. Revista de Saúde Pública, 31(2), 209-213.

Cassanti, A. C., Cassanti, A. C., Araújo, E. D., \& Ursi, S. (2008). Microbiologia democrática: Estratégias de ensinoaprendizagem e formação de professores. Enciclopédia Biosfera, 4(5), 1-23.

Fahnert, B. (2016). Edging into the future: Education in microbiology and beyond. FEMS Microbiology Letter, 363(7), pii:fnw048.

Firmanshah, I. F., Jamaluddin, J., \& Hadiprayitno, G. (2020). Learning difficulties in comprehending virus and bacteria material for senior high schools. JPBI (Jurnal Pendidikan Biologi Indonesia), 6(1), 165-172.

Freitas, A. S., Freitas, D. S., Silva, J. V., Silva, J. N., \& Santos, T. J. (2018). A Importância dos experimentos simples para as aulas de ciências e sua influência no processo de ensino aprendizagem. Diversitas Journal, 3(2), 329-335.

Gubert, F. A., Santos, A. C. L., Aragão, K. A., Pereira, D. C. R., Vieira, N. F. C., \& Pinheiro, P. N. C. (2009). Tecnologias educativas no contexto escolar: estratégia de educação em saúde em escola pública de Fortaleza-CE. Revista Eletrônica de Enfermagem, 11(1), 165-172.

Kaufmann, S., Santos, D. S., \& Correa, D. M. (2016). Cultura de bactérias: Análise da presença de microrganismos no ambiente escolar. Anais do Encontro sobre Investigação na Escola: "Educar para democracia e a justiça social", Uruguaiana, Rio Grande do Sul, 14. (pp. 27-28). Uruguaiana: UNIPAMPA.

Leite, B., \& Valente, P. A. (2020). Microbiologia e a extensão universitária. Revista Brasileira de Extensão Universitária, 11(1), 61-71.

Moresco, T. R., Carvalho, M. S., Klein, V., Lima, A. S., Barbosa, N. V., \& Rocha, J. B. (2017). Ensino de Microbiologia experimental para Educação Básica no contexto da formação continuada. Revista Electrónica de Enseñanza de las Ciencias, 16(3), 435-457.

Oliveira, H. M., \& Gonçalves, M. J. F. (2004). Educação em saúde: Uma experiência transformadora. Revista Brasileira de Enfermagem, 57(6), 761-763. 
Prates Junior, P., Silva, M. C. S., Melo, R. C. C, Lima, L. A., Araújo, K. S., Prado, I. G. O., Salgado, C. A., \& Martin, J. G. P. (2018). A microbiologia no contexto da agroecologia. Revista Brasileira de Extensão Universitária, 9(2), 75-82.

Como citar este artigo:

Felix, I. C. G., Brito, A. B., de Oliveira, T. F., Tavares, B. E. D., da Silva, K. F. S., da Silva, M. K., de Queiroz, A. C., \& Duarte, A. W. F. (2020). Socialização de conceitos de microbiologia no ensino fundamental através de atividades práticas. Revista Brasileira de Extensão Universitária, 11(2), 167-176. https://periodicos.uffs.edu.br/index.php/RBEU/article/ $\underline{\text { view/11365/pdf }}$ 